\title{
Pertumbuhan dan analisis kualitatif tanin, saponin dan flavonoid dari Selaginella plana, S. willdenovii and S. mayeri pada tiga naungan berbeda (The growth and qualitative analysis of tannin, saponin and flavonoid in Selaginella plana, S. willdenovii and S. mayeri under three kinds of shading treatment)
}

\author{
Tatik Chikmawati ${ }^{1)^{*}}$, Puspita Dewi Sopyati ${ }^{1}$, Miftahudin ${ }^{1)}$ \\ ${ }^{1)}$ Departemen Biologi, Fakultas Matematika dan IImu Pengetahuan Alam \\ Institut Pertanian Bogor. Jalan Agathis, Gedung Fakultas Peternakan Lt.5 W1, \\ Kampus IPB-Darmaga, Phone: 0251-8622833 \\ "Email korespondensi: tchikmawati@yahoo.com
}

Diterima 1 Januari 2013, diterima untuk dipublikasikan 2 Februari 2013

\begin{abstract}
Abstrak
Selaginella yang banyak dijumpai melimpah di Indonesia sangat berpotensi sebagai sumber antioksidan alami. Kadar bahan bioaktif dalam tumbuhan sangat tergantung pada lingkungan tumbuhnya, namun penelitian aspek budidaya dari Selaginella di Indonesia yang berkaitan dengan bahan bioaktif belum banyak dilakukan. Penelitian awal tentang aspek budidaya Selaginella telah dilakukan khususnya untuk mengetahui naungan yang tepat bagi pertumbuhannya serta pengaruhnya terhadap kandungan bahan bioaktif. Penelitian ini menggunakan rancangan petak terpisah dengan naungan sebagai petak utama dan jenis Selaginella sebagai anak petak. S. plana, S. willdenovii dan S. mayeri diberi perlakuan naungan dengan paranet $40 \%, 65 \%$, $80 \%$, dan tanpa naungan. Uji kandungan tanin, saponin, dan flavonoid secara kualitatif diketahui dengan melakukan ekstraksi dengan alkohol. Pertambahan cabang total, pertambahan bobot basah total, bobot basah, dan bobot kering biomassa dipengaruhi secara nyata oleh naungan dan jenis Selaginella. Masing-masing jenis Selaginella memerlukan intensitas cahaya yang berbeda untuk mendukung pertumbuhannya. Semua jenis yang diuji juga mengandung kadar tanin, saponin, dan flavonoid berbeda secara kualitatif.

Kata kunci: Selaginella, naungan, tanin, saponin, flavonoid
\end{abstract}

\begin{abstract}
Selaginella found abandonly in Indonesia is very potensial as the source of natural antioxidant. The amount of bioactive material of Selaginella depends on the environment, but research on the amount of bioactive material correlated to the cultivated aspect has not been done in Indonesia. The preeliminary research of the cultivation of Selaginella was investigated especially to know the right shading for the best growth of Selaginella. The right shading may also affect bioactive content of Selaginella. This research used split plot design with level of shading as main plot and species as sub plot. S. plana, S. willdenovii, and S. mayeri were grown under paranet with 40\%, 65\%, $80 \%$ shading, and non shading treatments. Bioactive compound was extracted using alcohol $70 \%$ and analyzed for tannin, saponin, and flavonoid contents. Results indicated that level of shading and species affected total branch increase, total fresh weight increase, fresh and dry weight of biomass. Each species required different light intensity to support its growth. All species in the experiment contained different qualitative level of tannin, saponin, and flavonoid.

Keywords: Selaginella, shade, tanin, saponin, flavonoid
\end{abstract}




\section{PENDAHULUAN}

Sudah

tumbuhan menjadi penyokong utama kesehatan umat manusia. Sekitar 60-75\% penduduk bumi menggantungkan kesehatannya pada tumbuhan. Penggunaan tumbuhan sebagai obat alternatif untuk pengobatan tradisional semakin meningkat dengan semakin mahalnya harga obat sintetik (Chikmawati \& Miftahudin 2011).

Salah satu tumbuhan paku yang melimpah di Indonesia dan telah digunakan sebagai bahan obat tradisional adalah Selaginella spp. (Dalimartha 2004). Beberapa jenis Selaginella diantaranya $S$. willdenovii, $S$. intermedia, dan $S$. ornata berpotensi sebagai antioksidan karena mengandung senyawa polifenol termasuk flavonoid (Chai \& Wong 2012; Chikmawati et al. 2013). Selaginella termasuk bangsa Selaginellales dari kelas Lycopodinae. Tumbuhan paku ini memiliki karakteristik yang khas yaitu batang dengan daun-daun berukuran kecil (microphyll) yang tersusun dalam garis spiral atau berhadapan dan tersusun dalam empat, dan sporangianya membentuk kerucut pada ujung percabangannya (Tjitrosoepomo 1994).

Selaginella dikenal sebagai tanaman obat tradisional Cina yang cukup penting dan dimanfaatkan baik di dalam maupun di luar negara Cina (de Winter \& Amoroso 2003). Cina telah membudidayakan $S$. tamaricana yang sudah diekspor ke Malaysia dan Jerman. Di Indonesia, tumbuhan dari marga Selaginella ini belum banyak dimanfaatkan sebagai tanaman obat (Chikmawati \& Miftahudin 2011), namun di Jawa Barat tumbuhan yang biasa disebut dengan nama Paku Rane ini banyak digunakan penduduk sebagai obat untuk mengobati beberapa penyakit seperti luka, patah tulang, dan juga pendarahan pasca persalinan.
Bahkan dalam industri jamu di tanah air, tumbuhan ini juga sudah menjadi salah satu bahan penyusun jamu.

Sebagian besar tumbuhan obat dikoleksi langsung dari alam (Joy et al. 1998). Demikian juga dengan Selaginella di Indonesia, penduduk biasanya memanfaatkan Selaginella liar yang berasal dari hutan. Kadar bahan bioaktif dalam Selaginella sangat tergantung dari lingkungan tumbuhnya sehingga jenis yang sama menghasilkan kadar bahan bioaktif berbeda jika berada dalam lingkungan berbeda, namun penelitian tentang budidaya tumbuhan ini di Indonesia belum pernah dilakukan. Mengingat Selaginella sering ditemukan pada lingkungan yang ternaungi maka tulisan ini menguraikan tentang hasil peneitian awal budidaya Selaginella dengan titik berat menggambarkan pengaruh naungan terhadap pertumbuhan dan kadar bahan bioaktif yang dikandung oleh tiga jenis Selaginella, $S$. plana, $S$. willdenovii dan S. mayeri.

\section{METODE Bahan}

Bahan tanaman yang digunakan adalah tiga jenis Selaginella yaitu $S$. plana, $S$. willdenovii, dan $S$. mayeri. Selaginella plana, $S$. willdenovii dikoleksi dari kampus IPB Dramaga, dan S. mayeri dikoleksi dari Kebun Raya Bogor.

\section{Rancangan Percobaan}

Penelitian ini menggunakan rancangan petak terpisah (split plot design) dengan naungan sebagai petak utama dan jenis Selaginella sebagai anak petak. Naungan terdiri dari empat taraf yaitu: 1) paranet $40 \%$ (intensitas cahaya 60\%), paranet $65 \%$ (intensitas cahaya $35 \%$ ), paranet $80 \%$ (intensitas cahaya 20\%), dan tanpa diberi naungan dengan intensitas cahaya $100 \%$. Jenis Selaginella yang 
digunakan terdiri dari tiga jenis yaitu: S. plana, S. willdenovii, dan $S$. mayeri. Setiap perlakuan diulang tiga kali.

\section{Penanaman}

Bagian batang Selaginella ditanam dalam polybag yang telah diisi media tanam yang tersusun atas tanah, sekam, dan pupuk organik dengan perbandingan $1: 1$ : 0,5 . Tanaman yang berhasil beradaptasi diberi perlakuan naungan dengan menggunakan paranet sesuai dengan perlakuan.

\section{Pengamatan Pertumbuhan}

Pengamatan awal dilakukan dengan menghitung jumlah cabang dan menimbang bobot basah batang tanaman yang akan ditanam pada awal penanaman. Pertambahan cabang diamati tiap minggu selama dua bulan, dan pertambahan cabang total yang diperoleh dari selisih jumlah pertambahan cabang awal dengan akhir. Pertambahan bobot basah total diperoleh dari selisih bobot basah awal dengan akhir dan di ukur pada saat panen. Suhu lingkungan rumah kaca, di bawah naungan, dan media tanam diukur setiap hari. Intensitas cahaya diukur pada pagi, siang, dan sore hari.

\section{Analisis Kandungan Tanin, Saponin dan Flavonoid secara Kualitatif}

Penyiapan ekstrak Selaginella dilakukan menggunakan prosedur Gayathri et al. (2005) dengan sedikit modifikasi. Seluruh bagian tumbuhan dikeringkan dan dihaluskan hingga menjadi tepung dengan menggunakan blender. Tepung kering Selaginella diekstrak dengan menggunakan pelarut alkohol 70\% (5 g/100 ml), kemudian dilakukan pengadukan tetap selama 4 jam menggunakan stirer, dan disaring menggunakan kertas saring. Filtrat kemudian dikeringkan dengan cara menguapkannya pada evaporator berputar pada suhu $60^{\circ} \mathrm{C}$ selama 6 jam dan dioven pada suhu $60^{\circ} \mathrm{C}$ selama 24 jam.

Metode analisis bahan bioaktif dilakukan berdasarkan metode Harborne (1987) dimulai dengan menyiapkan $5 \mathrm{~g}$ sampel serbuk kering dalam tabung reaksi dan menambahkan akuades $5 \mathrm{ml}$ per 0.1 g sampel, kemudian dipanaskan selama 5 menit dalam waterbath dan disaring. Filtrat dibagi tiga dan masing-masing diberi perlakuan berbeda untuk uji keberadaan tanin, saponin, dan flavonoid. Dalam uji tanin, filtrat ditambah 3 tetes $\mathrm{FeCl}_{3}$ $10 \%$ dan dinyatakan positif apabila terbentuk warna hitam kehijauan. Dalam uji saponin, filtrat dikocok kuat-kuat beberapa kali, hasil dinyatakan positif apabila buih yang terbentuk stabil. Dalam uji flavonoid, filtrat ditambah dengan serutan/serbuk magnesium, 5 tetes $\mathrm{HCl}$ pekat, dan 5 tetes amil alkohol. Hasil dinyatakan positif apabila lapisan amil alkohol (lapisan atas) berwarna jingga.

\section{HASIL DAN PEMBAHASAN}

\section{Warna Daun}

Pemberian naungan menyebabkan perbedaan warna daun pada ketiga jenis Selaginella (Tabel 1). Pada S. plana, semakin rapat naungan semakin pekat warna hijau daunnya. Pada naungan $80 \%$ daun $S$. willdenovii berwarna hijau keunguan, sedangkan pada naungan $0 \%$ daun berwarna coklat kehijauan. Namun, warna daun $S$. mayeri hampir sama pada semua perlakuan. Menurut Tjondronegoro et al. (1985) pemberian cahaya penuh pada jenis tanaman toleran naungan dapat merusak sistem pigmennya karena terjadi peristiwa fotooksidasi. Selain pengaruh solarisasi, sebagian besar tumbuhan 
Tabel 1. Perbedaan warna daun tiga jenis Selaginella pada beberapa tingkat naungan

\begin{tabular}{clll}
\hline Naungan & S. plana & S. willdenis & \\
& Hijau kekuningan & Coklat kehijauan & S. mayeri \\
$40 \%$ & Hijau muda & Hijau & Hijau muda \\
$65 \%$ & Hijau sedikit pekat & Hijau & Hijau muda \\
$80 \%$ & Hijau pekat & Hijau keunguan & Hijau muda \\
\hline
\end{tabular}

membentuk pigmen antosianin dan flavonoid lainnya dalam beberapa sel yang terspesialisasi di salah satu atau beberapa organnya. Proses ini sering terpacu oleh cahaya (Salisbury \& Ross 1995). Hal ini dibuktikan dengan terdapatnya flavonoid pada semua jenis Selaginella yang diamati.

\section{Pertambahan Cabang}

Pertambahan cabang jenis Selaginella diamati dari jumlah seluruh cabang yang tumbuh tiap minggu. Selaginella plana tumbuh dengan baik pada perlakuan naungan $65 \%$ dan $40 \%$, namun pertumbuhan terbaik pada perlakuan naungan $65 \%$ dan pertumbuhan terendah ditunjukkan oleh perlakuan naungan $\quad 80 \% \quad$ (Gambar 1). Penyeragaman tanaman awal dilakukan berdasarkan bobot cabang tanaman. Sehingga titik awal pertumbuhan $S$. willdenovii menjadi kurang seragam. Pertambahan cabang S. willdenovii menunjukkan hasil yang sama pada perlakuan naungan 40\%, 65\%, dan kontrol, dengan laju pertumbuhan tertinggi pada naungan $40 \%$. Laju pertumbuhan terendah pada $S$. willdenovii ditunjukkan oleh naungan $80 \%$ (Gambar 2).Pertambahan cabang $S$. mayeri mengalami peningkatan secara nyata pada minggu ke-6 hingga 9 pada perlakuan tanpa naungan, diikuti oleh perlakuan naungan $40 \%$. Berbeda dengan dua jenis lainnya, pada $S$. mayeri pertambahan cabang tertinggi ditunjukkan oleh perlakuan tanpa naungan (Gambar $3)$.

Hasil analisis ragam menunjukkan bahwa pertambahan cabang total dipengaruhi sangat nyata oleh perbedaan jenis Selaginella $\quad(\operatorname{Pr}<0,05), \quad$ dan dipengaruhi nyata oleh perbedaan tingkat naungan dan interaksi antara jenis dan tingkat naungan. Pertambahan cabang total tertinggi pada $S$. plana terjadi dibawah naungan $65 \%$, pada $S$. willdenovii terjadi dibawah naungan $40 \%$, sedangkan pada $S$. mayeri terjadi pada perlakuan tanpa naungan (Tabel 2).

\section{Pertambahan Bobot Basah Total}

Pertambahan bobot dipengaruhi oleh jenis Selaginella dan tingkat naungan ( $\operatorname{Pr} \leq 0.05)$, tetapi tidak dipengaruhi oleh interaksi antara keduanya. S. plana menunjukkan pertambahan bobot basah total terbesar. Naungan $40 \%$ dan 65\% memberikan pengaruh relatif sama terhadap bobot basah total. 


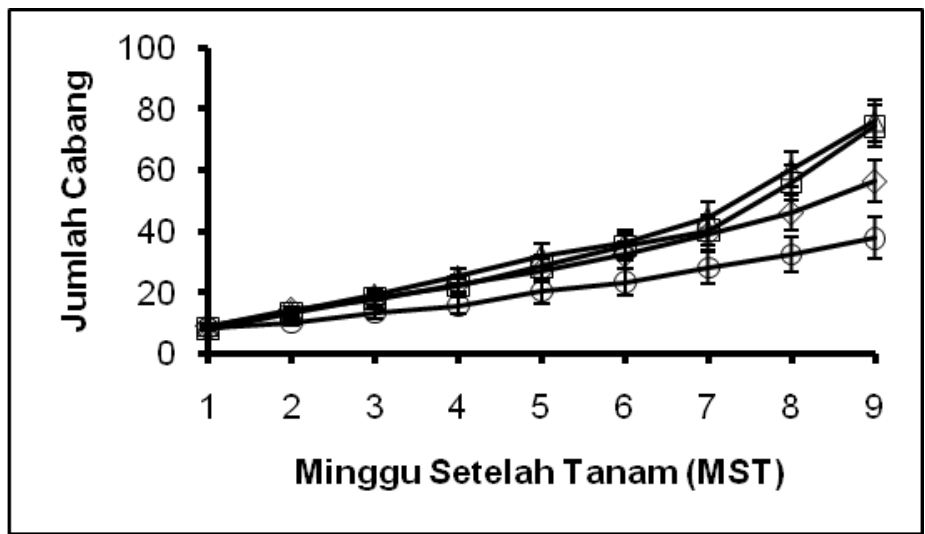

Gambar 1. Pertambahan jumlah seluruh cabang $S$. plana di beberapa tingkat naungan. -- $\diamond--=$ tanpa naungan, $\quad--\square--=$ naungan $40 \%$, $--\triangle--=$ naungan $65 \%$, dan $--\bigcirc--=$ naungan $80 \%$

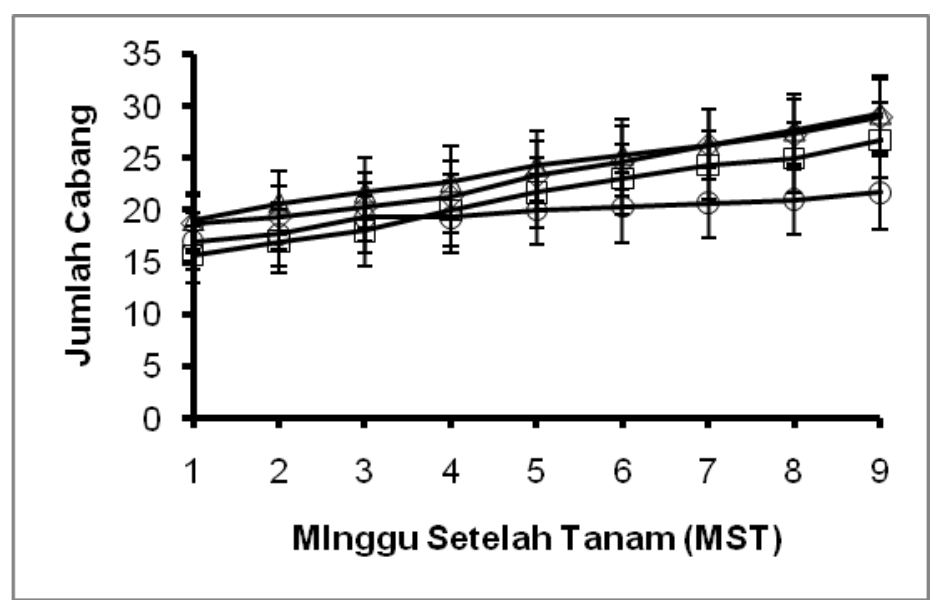

Gambar 2. Pertambahan jumlah seluruh cabang pada $S$. willdenovii di beberapa tingkat naungan. . -- $\diamond--=$ tanpa naungan, $\quad--\square--=$ naungan $40 \%$, -- $\triangle--=$ naungan $65 \%$, dan --○-- = naungan $80 \%$

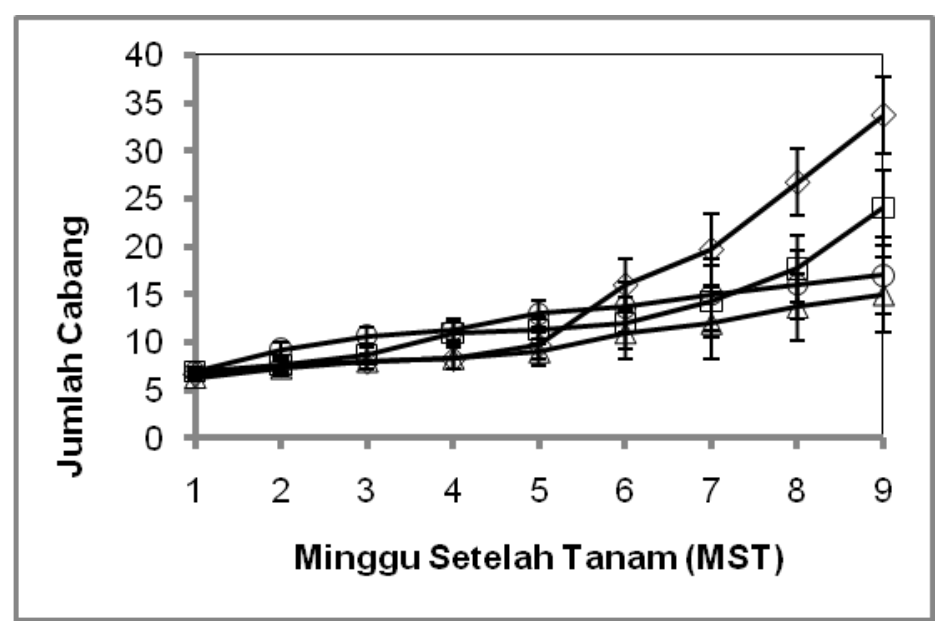

Gambar 3. Pertambahan jumlah seluruh cabang pada S. mayeri di berbagai naungan. . -- $\diamond--=$ tanpa naungan, $\quad--\square--=$ naungan $40 \%$, $--\triangle--=$ naungan $65 \%$, dan $--\bigcirc--=$ naungan $80 \%$ 
Tabel 2. Pertambahan cabang total tiga jenis Selaginella pada beberapa tingkat naungan

\begin{tabular}{llcll}
\hline \multirow{2}{*}{ Naungan } & \multicolumn{3}{c}{ Jenis } & \multirow{2}{*}{ Rataan } \\
\cline { 2 - 4 } & S. plana & S. willdenovii & S. mayeri & \\
\hline $0 \%$ & $47.3 \mathrm{~b}$ & $10.3 \mathrm{~d}$ & $27.0 \mathrm{c}$ & $28.2 \mathrm{a}$ \\
$40 \%$ & $66.3 \mathrm{a}$ & $11.0 \mathrm{~d}$ & $17.0 \mathrm{~cd}$ & $31.4 \mathrm{a}$ \\
$65 \%$ & $67.0 \mathrm{a}$ & $10.3 \mathrm{~d}$ & $8.7 \mathrm{~d}$ & $28.7 \mathrm{a}$ \\
$80 \%$ & $29.3 \mathrm{c}$ & $4.7 \mathrm{~d}$ & $10.0 \mathrm{~d}$ & $14.7 \mathrm{~b}$ \\
Rataan & $52.5 \mathrm{a}$ & $9.08 \mathrm{~b}$ & $15.7 \mathrm{~b}$ & \\
\hline
\end{tabular}

Keterangan: Angka yang diikuti oleh huruf yang sama tidak berbeda nyata pada taraf uji $5 \%$ DMRT

\section{Bobot basah dan bobot kering saat panen}

Bobot basah dan bobot kering dipengaruhi oleh naungan $(\operatorname{Pr}<0,05)$ dengan bobot basah dan bobot kering tertinggi berturut-turut diperoleh pada naungan $65 \%$ dan tanpa naungan. Bobot basah dan bobot kering juga dipengaruhi secara nyata oleh jenis Selaginella. $S$. plana memiliki bobot lebih tinggi dari S. willdenovii, namun tidak dipengaruhi oleh interaksi antara keduanya (Tabel 3).

Berdasarkan hasil pengamatan terhadap pertumbuhan Selaginella spp. menunjukkan bahwa masingmasing jenis Selaginella memerlukan intensitas cahaya yang berbeda untuk mendukung pertumbuhannya. S. plana mempunyai pertambahan cabang tertinggi pada perlakuan naungan $65 \%$, S. willdenovii pada naungan $40 \%$, dan S. mayeri pada perlakuan tanpa naungan. Data tersebut mengindikasikan bahwa $S$. plana dan $S$. willdenovii lebih menyukai lingkungan yang ternaungi, sedangkan $S$. mayeri lebih menyukai lingkungan yang lebih terbuka. Namun, pertumbuhan ketiga jenis Selaginella terhambat pada naungan $80 \%$. Dengan demikian dapat disimpulkan bahwa meskipun Selaginella spp. menyukai hidup ternaungi, namun masih memerlukan cahaya untuk berfotosintesis dengan intensitas berbeda tergantung kebutuhan masing-masing jenisnya.

Bobot kering rata-rata dari ketiga jenis Selaginella memiliki nilai tertinggi pada perlakuan tanpa naungan. Menurut Tei et al. (1996) tanaman yang menyukai naungan mempunyai laju asimilasi bersih tinggi pada tingkat intensitas radiasi matahari rendah, karena fotorespirasi dan respirasi rendah pada kondisi tersebut, sedangkan pada percobaan ini bobot kering tertinggi ketiga jenis Selaginella terdapat pada perlakuan tanpa naungan. Menurut pendapat Harjadi (1991), besarnya cahaya yang tertangkap pada proses fotosintesis menunjukkan biomassa, sedangkan besarnya biomasa dalam jaringan tanaman mencerminkan bobot kering. Dengan demikian menurunnya intensitas cahaya yang disebabkan oleh naungan paranet berpengaruh pada bobot kering Selaginella.
Analisis tanin, saponin dan flavonoid secara kualitatif
Kandungan kualitatif tanin terkecil terdapat pada S. willdenovii pada naungan $40 \%$ dan tanpa naungan. Sedangkan kandungan saponin pada S. willdenovii seacra kualitatif lebih tinggi pada semua perlakuan naungan dibandingkan tanpa naungan. 
Tabel 3 Pertambahan bobot basah total, bobot basah dan kering biomasa dari tiga jenis Selaginella pada beberapa tingkat naungan

\begin{tabular}{cccc}
\hline Perlakuan & $\begin{array}{c}\Delta \text { Bobot } \\
\text { Basah total }\end{array}$ & $\begin{array}{c}\text { Bobot } \\
\text { basah }\end{array}$ & $\begin{array}{c}\text { Bobot } \\
\text { kering }\end{array}$ \\
\hline $\begin{array}{c}\text { Naungan } \\
0 \%\end{array}$ & $1.867 \mathrm{a}$ & $2.667 \mathrm{a}$ & $0.657 \mathrm{a}$ \\
$40 \%$ & $1.567 \mathrm{ab}$ & $2.344 \mathrm{a}$ & $0.583 \mathrm{a}$ \\
$65 \%$ & $1.922 \mathrm{a}$ & $2.711 \mathrm{a}$ & $0.588 \mathrm{a}$ \\
$80 \%$ & $0.718 \mathrm{~b}$ & $1.473 \mathrm{~b}$ & $0.317 \mathrm{~b}$ \\
Jenis & & & \\
S. plana & $2.417 \mathrm{a}$ & $3.650 \mathrm{a}$ & $0.850 \mathrm{a}$ \\
S. willdenovii & $1.817 \mathrm{a}$ & $2.683 \mathrm{~b}$ & $0.633 \mathrm{~b}$ \\
S. mayeri & $0.322 \mathrm{~b}$ & $0.563 \mathrm{c}$ & $0.126 \mathrm{c}$ \\
\hline
\end{tabular}

Keterangan : Angka yang diikuti oleh huruf yang sama tidak berbeda nyata pada taraf uji 5\% DMRT

Pada perlakuan tersebut, kandungan saponin secara kualitatif pada $S$. willdenovii juga paling tinggi dibandingkan dengan jenis lainnya. Kandungan kualitatif flavonoid terbesar terdapat pada $S$. plana dengan perlakuan naungan $65 \%$. Jika dibandingkan dengan Selaginella yang dikoleksi dari alam, Selaginella yang ditanam di rumah kaca cenderung memiliki kandungan tanin dan saponin yang lebih tinggi secara kualitatif. Demikian juga kandungan flavonoid $S$. willdenovii dan $S$. mayeri yang ditanam di rumah kaca lebih tinggi daripada yang diambil dari alam. Akan tetapi $S$. plana memiliki kandungan bahan aktif yang hampir sama antara tanaman yang ditanam dirumah kaca dan yang diambil dari alam (Tabel 4).

Secara umum, Selaginella yang ditanam di rumah kaca memiliki kandungan bahan aktif secara kualitatif lebih tinggi dari tanaman yang dikoleksi dari alam. Tingginya suhu di rumah kaca mengakibatkan tanaman yang ditanam mengalami cekaman sehingga membentuk metabolit sekunder yang lebih banyak. Menurut Lambers et al. (1998) konsentrasi kandungan metabolit sekunder tanaman tergantung pada umur tanaman seperti halnya faktor abiotik lingkungan seperti intensitas cahaya, stress air, kelebihan air, pembekuan, polusi, dan suplai nutrisi. Perlakuan naungan yang diberikan mempengaruhi intensitas cahaya yang diterima oleh tanaman sehingga mengakibatkan cekaman. Selain intensitas cahaya, pemberian naungan juga mempengaruhi suhu media tanam. Suhu media tanam pada perlakuan tanpa naungan lebih tinggi daripada suhu media tanam dengan perlakuan naungan. Menurut Widiastuti et al. (2004) perbedaan tingkat naungan mempengaruhi intensitas cahaya, suhu udara, kelembaban udara,dan suhu tanah lingkungan tanaman, sehingga intensitas cahaya yang diterima oleh tanaman berbeda dan mempengaruhi ketersediaan energi cahaya yang akan diubah menjadi energi panas dan energi kimia.

Selain mengandung tanin dan saponin, ekstrak Selaginella juga mengandung flavonoid. Senyawa flavonoid yang merupakan salah satu golongan dari polifenol sampai saat ini belum dimanfaatkan secara optimal dan masih digunakan secara terbatas. Hal ini dikarenakan senyawa flavonoid tidak stabil terhadap perubahan pengaruh oksidasi, cahaya, dan perubahan kimia, sehingga apabila teroksidasi strukturnya akan berubah dan fungsinya sebagai bahan aktif akan menurun bahkan hilang dan kelarutannya rendah (Handayani \& Sulistyo 2008). 
Tabel 4. Kandungan kualitatif senyawa bioaktif dari S. plana, S. willdenovii, dan S. mayeri pada empat tingkat naungan dan di alam

\begin{tabular}{|c|c|c|c|c|c|c|c|c|c|}
\hline \multirow{2}{*}{ Naungan } & \multicolumn{3}{|c|}{ S. plana } & \multicolumn{3}{|c|}{ S. willdenovii } & \multicolumn{3}{|c|}{ S. mayeri } \\
\hline & $\mathrm{T}$ & $\mathrm{s}$ & $\mathrm{F}$ & $\mathrm{T}$ & $S$ & $\mathrm{~F}$ & $\mathrm{~T}$ & $\mathrm{~s}$ & $\mathrm{~F}$ \\
\hline $0 \%$ & ++++ & + & ++ & + & ++++ & ++ & ++ & + & +++ \\
\hline $40 \%$ & +++ & ++ & +++ & + & ++++ & ++ & +++ & +++ & +++ \\
\hline $65 \%$ & ++++ & ++ & ++++ & ++ & ++++ & +++ & +++ & +++ & ++ \\
\hline $80 \%$ & ++++ & + & +++ & ++ & ++++ & +++ & +++ & +++ & ++ \\
\hline Alam & +++ & + & +++ & ++ & - & + & ++ & +++ & + \\
\hline \multicolumn{10}{|c|}{$\begin{array}{c}\text { Keterangan: } \mathrm{T}=\text { tanin, } \mathrm{S}=\text { saponin, } \mathrm{F}=\text { fla } \\
\text { Banyak, }++++: \text { Sangat banyak }\end{array}$} \\
\hline \multicolumn{5}{|c|}{ Kandungan metabolit sekunder } & \multicolumn{2}{|c|}{ nomer } & \multicolumn{3}{|c|}{ DP2M/III/2007. } \\
\hline
\end{tabular}

bergantung pada faktor lingkungan tempat tumbuh seperti iklim, lokasi, tanah, faktor dari dalam tumbuhan tersebut seperti jenis atau varietas, bagian yang diekstraksi dan umurnya, prosedur pemanenan, dan ekstraksi (Nahrstedt dan Butterweck 1997).

\section{KESIMPULAN}

Masing-masing

jenis Selaginella memerlukan intensitas cahaya yang berbeda untuk mendukung pertumbuhannya. Pertumbuhan terbaik $S$. plana pada perlakuan naungan $65 \%, S$. willdenovii pada naungan $40 \%$, dan S. mayeri pada perlakuan tanpa naungan. Kandungan tanin, saponin, dan flavonoid Selaginella spp. secara kualitatif bervariasi tergantung pada jenis dan tingkat naungan. Kandungan tanin terbanyak secara kualitatif diperoleh pada S. plana dengan perlakuan naungan $65 \%, 80 \%$, dan tanpa naungan. Kandungan saponin terbanyak secara kualitatif pada $S$. willdenovii. Kandungan flavonoid terbanyak secara kualitatif pada $S$. plana dengan naungan 65\%.

\section{UCAPAN TERIMAKASIH}

Penelitian ini adalah bagian dari Penelitian Fundamental yang didanai oleh Direktorat Umum Pendidikan Tinggi Indonesia atas nama Dr. Tatik Chimawati dengan

\section{DAFTAR PUSTAKA}

Chai TT and Wong FC (2012) Antioxidant properties of aqueous extracts of Selaginella willdenowii. Journal of Medicinal Plants Research 6(7): 1289-1296. DOI: 10.5897/JMPR11.1376

Chikmawati T, Miftahudin (2011) Keanekaragaman Selaginella dari Pulau Jawa. Seminar, Konggres dan Simposium Nasional Penggalang Taksonomi Tumbuhan Indonesia ke-IX. Kebun Raya Eka Karya, Bali 11-13 Oktober

Chikmawati T, Setyawan AD. Miftahudin (2013) Phytochemical composition of Selaginella spp from Java Island Indonesia. Makara in press

Dalimartha S (2004) Atlas tumbuhan obat. Jilid 1. Trubus Agriwidya. Jakarta. 120p

de Winter WP, Amoroso VB, editor (2003) Plant resources of South-East Asia No. 15 (2). Cryptogams: Fern and Ferns allies. Prosea Foundation. Bogor

Gayathri V, Asha VV, Subramonian A (2005) Preliminary studies on the immunomodulatory and antioxidant properties of Selaginella. Indian Pharmacol 37: 381-385 
Handayani R, Sulistyo J (2008) Sintesis senyawa flavonoida-glikosida secara reaksi tranglikosilasi enzimatik dan aktivitasnya sebagai antioksidan. Biodiversitas $9(1): 1-4$

Harborne JB (1987) Metode fitokimia. Penebit ITB. Bandung

Harjadi SS. (1991) Pengantar agronomi. Gramedia. Jakarta Joy PP et al. (1998) Medicinal plant. Kerala Agricultural University. Kerala

Lambers H, Chapin FS, Pons TL (1998) Plant physiological ecology. New York: Springer

Nahrstedt, Butterweck (1997) Biologically active and other chemical constituents of the herb of Hypericum perforatum L. Pharmaceutical Bulletin 30(2): 379-381

Salisbury FB, Ross CW (1995) Fisiologi Tumbuhan. Diah RL, Sumaryono,
(Penerjemah) Penerbit ITB. Bandung

Tei FA, Scaife A, Aikman DP (1996) Growth of lettuce, onion, and red beet. I. Growth analysis, light interception, and radiation use efficiency. Ann. Bot. 78:633-643

Tjitrosoepomo G (1994) Taksonomi tumbuhan. PT Bhratara Karya Aksara. Jakarta

Tjondronegoro PD, Harran S, Fauzan (1985) Pengaruh naungan dan pemberian pupuk terhadap pertumbuhan semai meranti (Shorea Pinanga Scheeff., $S$. Leprosura Mig.). Laporan Hasil Penelitian. FMIPA, IPB. Bogor

Widiastuti L, Tohari, Sulistyaningsih E (2004) Pengaruh intensitas cahaya dan kadar daminosida terhadap iklim mikro dan pertumbuhan tanaman krisan dalam pot. $J$ IImu Pertanian 11(2):35-42 